\title{
Acute Salivary Gland Enlargement Following Instrumentation of the Upper Airway
}

\author{
Major N F Strowbridge, \\ $M B, B S, D A, R A M C$, Specialist in Anaesthesia \\ Queen Elizabeth Military Hospital, Woolwich, London SE18
}

SUMMARY: A case of sudden enlargement of the submandibular and parotid salivary glands following endotracheal intubation is described. The literature concerning this condition is reviewed, and the possible causes are discussed.

\section{Case Report}

A 48 year old housewife was admitted for oesophagoscopy and Heller's myotomy. Achalasia of the oesophagus had been diagnosed in 1975 at which time a previous Heller's operation had been performed. She continued to have symptoms, and underwent five dilatations of the oesophagus between 1977 and 1982 . She had a long history of Raynaud's syndrome and had undergone bilateral lumbar sympathectomy. Further medical history included tonsillectomy, hysterectomy, and haemorrhoidectomy. There was no record of abnormal reactions occurring during any of the previous operations.

On admission she complained of dysphagia but was otherwise well. Her weight was stable. Current drug treatment consisted of flurazepam at night. She denied knowledge of any allergies. Examination showed an obese anxious lady. Her fingers were blue and cold but her cardiovascular system was otherwise normal. There were no abnormalities of the respiratory system. Pulmonary function tests, chest X-rays, and ECG were also normal. Premedication with papaveretum $15 \mathrm{mg}$ and hyoscine $0.3 \mathrm{mg}$ was given intramuscularly.

Induction of anaesthesia with Diazemuls $2.5 \mathrm{mg}$, thiopentone $250 \mathrm{mg}$, and suxamenthonium $100 \mathrm{mg}$ was followed by uneventful tracheal intubation with a 7.0 Portex endotracheal tube. Fentanyl $50 \mu \mathrm{g}$ and pancuronium $6 \mathrm{mg}$ were given and she was ventilated with nitrous oxide and oxygen whilst oesophagoscopy was performed. At the end of this procedure, some twenty five minutes after induction, it was noticed that there was swelling of the right side of the neck. This swelling visibly increased over the next ten minutes. Palpation revealed definite enlargement of the right submandicular and parotid glands. There was some enlargement of the left side, but to a lesser extent.

Throughout this period her blood pressure remained stable with a systolic pressure between 120 and 140 $\mathrm{mmHg}$ and a pulse rate between 80 and 90 beats per minute. There was slight oedema of the eyelids, but she was not flushed and there was no skin rash. Auscultation of the lung fields was normal and there was no change in the inflation pressure. Laryngoscopy showed no swelling of the larynx nor pharynx. Blood taken for amylase estimation, at this stage, showed a plasma amylase of $500 \mathrm{IU} / \mathrm{l}(\mathrm{N}=70-330)$.
Despite the absence of any other signs of an allergic reaction she was given chlorpheniramine $10 \mathrm{mg}$ and hydrocortisone $100 \mathrm{mg}$ intravenously. The trachea was reintubated with a small right Robertshaw double lumen tube. All systems remained stable throughout the three hour operation of the Heller's myotomy, and no increased swelling of the neck was noted.

A further sample of blood was taken in the recovery area. The plasma amylase had decreased to 360 IU/l. The swelling had begun to subside but the glands were still easily palpable. After six days there was no palpable enlargement of the glands and the plasma amylase was $370 \mathrm{IU} / 1$.

\section{Discussion}

The degree and abrupt onset of the swelling led to the initial suspicion that it was due to trauma caused duringo either laryngoscopy, intubation, or oesophagoscopy. However, palpation of the enlarged glands immediately excluded this diagnosis and the swelling was thought to be due to an adverse drug reaction. Salivary gland enlargement has been associated with several drugs. Gross ${ }^{1}$ described swelling of the parotid and submandibular glands following the administration of oxphenbutazone. The condition was originally diagnosed as mumps but rapidly resolved following withdrawal of the drug. Further provocation with the drug a year later, produced the same result. Imbur and Bourne ${ }^{2}$ also describe rapid enlargement of the salivary glands three hours after the injection of iodinecontaining contrast medium. Within forty eight hours, the glands had returned to their original size. The hypotensive agents bretylium, guanethidine, bethanidine $^{3}$ and methyl dopa ${ }^{4}$ have also been implicated. None of these adverse drug reactions, however, were of such an acute onset as in the case described.

Benign transient swelling of either the submandibular or parotid glands has been reported. Attas et $\mathrm{al}^{5}$ described the phenomenon in 1968 when they reported enlargement of all the salivary glands following tracheal intubation in an obese black woman. The glands decreased in size over the next thirty minutes. A further six cases were described but the authors were unable to relate the swelling to age, sex, race, type of surgery or past medical history. Further work also failed to show 
any correlation between gland enlargement and the administration of atropine and suxamethonium, the only drugs common to all cases. Transient swelling was associated with straining during intubation in one case and after extubation in another four.

Bonchek ${ }^{6}$ described a case where massive bilateral enlargement of the parotid, submandibular, and sublingual glands occurred five minutes after intubation following suxamethonium. The enlargement was so great that it was deemed necessary to perform a tracheostomy as it seemed likely that the airway would be inadequate if the endotracheal tube was removed. The swelling persisted for five days. A further general anaesthetic was given two weeks later. Thiopentone, suxamethonium and intubation were all avoided, anaesthesia being induced with halothane via the tracheostomy. There was no recurrence of the swelling.

Reilly ${ }^{7}$ reported three cases of which only two had been intubated. Straining occurred on the tube on emergence, after which the swellings were noted. In one case the swelling was barely palpable after two hours but in the other it persisted for seventy two hours. Plasma amylase levels measured during the first three days were all normal although it was not stated when the first sample was taken. The third case was unusual as the patient had not been intubated. The swelling was noted in the recovery area and persisted for forty eight hours.

Couper $^{8}$ describes four cases of parotid enlargement in patients who had undergone oesophagoscopy for possible carcinoma of the oesophagus. He could find no relationship between the swelling and age, general condition, sex or premedication. A further three cases described by Wakayama et al $^{9}$ showed parotid and submandibular gland enlargement either during or immediately after anaesthesia. The swellings disappeared without any treatment within eight to sixty hours. Several cases have been described following peroral endoscopy with both rigid and flexible endoscopes $^{10,11}$. Not all patients underwent general anaesthesia; Martin ${ }^{12}$ describes a case of swelling following oesophageal dilation under intravenous diazepam.

Several possible mechanisms have been suggested that might account for this phenomenon. Attas and his co-workers ${ }^{5}$ originally thought that it might be due to the combination of atropine and suxamethonium, but could find no correlation on further studies. They did demonstrate, however, that coughing and straining on an endotracheal tube could produce slight swelling of the salivary glands for three to five minutes. Reilly ${ }^{7}$ and Matsuki et al $^{13}$ also considered straining to be of importance, but this is not a constant feature of these reports and the swelling produced seems to be of a more transient nature.

Couper $^{8}$ felt that manipulation of the head during oesophagoscopy may give rise to obstruction of the thoracic inlet venous drainage with subsequent congestion of the parotid glands.
Wakayama $^{9}$ and Slaughter ${ }^{10}$ and their co-workers have postulated mechanical obstruction of the salivary ducts but Slaughter ${ }^{14}$ later described a further case and found it difficult anatomically to ascribe this to duct occulsion. It would seem unlikely that this is a possible cause.

Bonchek ${ }^{6}$ considered several explanations. These included the possibility that the swelling was due to an adverse drug reaction. The most likely candidate was suxamethonium, but, whilst this might have caused massive secretion, it did not explain the glandular enlargement, unless there was oedema of the lining cells of the duct. He considered that a more likely explanation was involvement of a reflex arc, with the afferent stimulus coming from the tongue, mouth or pharynx during intubation, and the efferent impulses (of far more intense quality than usual) being carried through the fibres of the glossopharyngeal nerve. The enlargement of the glands might have been due to the striking vasodilation and hyperaemia that parasympathetic stimulation can produce.

The physiology of the salivary glands and the control of their secretions has been well documented. The glands receive efferent fibres from both the sympathetic and parasympathetic nervous systems. The maines secretory innervation is parasympathetic from the salivary nucleus via the facial nerve, chorda tympani ando lingual nerve to the submandibular and sublinguad glands, and via the glossopharyngeal nerve to them parotid glands. Parasympathetic stimulation iso accompanied by vasodilation, which unlike the secretory reponse, is not blocked by atropine. Hiltong and Lewis $^{15}$ have shown in the cat that chordas. stimulation releases a proteolytic enzyme from the glancs cells which acts on plasma globulins in the interstitiaf fluid to release the vasodilator polypetide, bradykinin.

In animal studies it has been found that distension of the oesophagus is a potent stimulus to salivation, as is chronic irritation resulting from disease in humans ${ }^{16}$. Unilateral stimulation produces a greater response on the stimulated side but some effect on the opposite side. Even if the stimuli are equal, the response may be stronger on one side than the other. This would account for the fact that this condition is often unilateral.

\section{Conclusions}

Many explanations have been advanced as to the possible cause of this condition. The initial theory that it may be due to an adverse drug reaction seems unlikely as no individual drug has been used in all of the reported cases. Coughing and straining on the endotracheal tube would seem to produce some enlargement of the salivary glands but this is of much shorter duration. Once again, straining is not a constant feature of these reports.

Salivary gland enlargement seems to occur, in the majority of cases, in response to instrumentation of the upper airway or oesophagus. Thus the most likely explanation is that instrumentation stimulates an 
unusually powerful reflex arc resulting in hyperaemia of the glands.

In all of the cases described, the swelling has subsided without treatment, and apart from one case where tracheostomy was performed to ensure a patent airway, has never given rise to any further problems. The anaesthetist and patient can be assured that this is a benign and transient condition.

\section{REFERENCES}

1. Gross L. Oxphenbutazone induced parotitis. Ann Intern Med 1969; 70: 1229-30.

2. Imbur D J and BOURNE R B. Iodide mumps following excretory urography. J Urol 1972; 108: 629-30.

3. KLEIN F. Hypotensive drugs. In: Meyler L, Herxheimer A, eds. Side effects of Drugs. Vol 7. Amsterdam: Excerpta Medica, 1972: 297-306.

4. Mardh P, A Belfrage I and Navertsten E. Sialadenitis following treatment with Alpha Methyl Dopa. Acta Med Scand $1974 ; 195$ : 333.

5. AtTas M, Sabawala P B and Keats A S. Acute transient sialadenopathy during induction of anaesthesia. Anaesthesiology 1968; 29: 1050-52.

6. BONCHEK L I. Salivary gland enlargement during induction of anaesthesia. JAMA 1969; 209: 1716-18.

7. REILly D J. Benign transient swelling of the parotid glands following general anaesthesia. 'Anaesthesia mumps'. Anesth Analg 1970; 49: 560-63.

8. COUPER J L. Benign transient enlargement of the parotid glands associated with anaesthesia. S Afr Med J 1973; 47: 316-18.

9. WAKAYAMA $S$, et al. Three cases of salivary gland swelling developing during and immediately after general anaesthesia. Jpn J Anaesthesiol 1973; 22: 1417-21.

10. Slaughter R L and BOyce H W. Submaxillary salivary gland swelling developing during peroral endoscopy. Gastroenterology 1969; 57: 83-88.

11. BLACKFORD R W. Recurrent swelling of the patotid and submaxillary glands following bronchoscopy. Ann Otol Rhinol Laryngol 1944; 53: 54.

12. MARTIN D. Salivary gland enlargement during oesophageal stricture dilation. Postgrad Med J 1980; 56: 187-89.

13. Matsuki A, Wakayama $S$ and Oyama T. Acute transient swelling of the salivary glands during and following endotracheal anaesthesia. Anaesthetist 1975; 24: 125-8.

14. Slaughter R L. Parotid gland swelling developing during peroral endoscopy. Gastrointest Endosc 1975; 22: 38-39.

15. Hilton $S$ M and Lewis $G$ P. The mechanism of the functional hyperaemia in the submandibular salivary gland. J Physiol 1955; 129: 253-71.

16. NeIl Jenkins G. The Physiology and Biochemistry of the Mouth. 4th ed. London: Blackwell, 1978. 